\title{
Research on the Characteristics of Modern Advertising Culture
}

\author{
Yangyang Qin \\ Mianyang Teachers' College, Mianyang, China \\ Email: yy1010123650@163.com
}

How to cite this paper: Qin, Y.Y. (2019) Research on the Characteristics of Modern Advertising Culture. Open Journal of Social Sciences, 7, 362-366.

https://doi.org/10.4236/jss.2019.78026

Received: July 15, 2019

Accepted: August 24, 2019

Published: August 27, 2019

Copyright $\odot 2019$ by author(s) and Scientific Research Publishing Inc. This work is licensed under the Creative Commons Attribution International License (CC BY 4.0).

http://creativecommons.org/licenses/by/4.0/

\begin{abstract}
Currently, advertising is everywhere in the media environment we are in. Our lives are full of advertising, and advertising is an integral part of our lives. French advertising critic Robert Grange said, "We breathe nitrogen, oxygen and advertising every day". Advertising is more than just a means of propaganda and business. It has its own distinctive characteristics of the times and is not acceptable. Neglected cultural phenomena, modern advertising culture has distinct characteristics of the times and traces of social life.
\end{abstract}

\section{Keywords}

Modern Advertising Culture, Mass Media, Feminism

\section{A Modern Advertising Culture under the Perspective of Mass Media}

At present, with the development of media technology, our life has become the world of the screen [1]. Whether it's a TV, a mobile phone or a whimsical electronic screen in an alley, advertising is a beautiful urban landscape. From ancient times to today, no matter how many changes have taken place in the form of advertising, its basic components are advertisers, advertising content, advertising audiences, and the forms and means of advertising. These elements bear the brand of social culture and are accompanied by Historical change advertisements are also adjusting their position in the cultural form in time, constantly updating and transforming. As a cultural phenomenon, advertising has an important impact on all aspects of our social life and changes our way of life and ideas. "Advertising culture is an organic part of the whole cultural system. It is the inheritance of history and traditional culture. It is a reflection of the political, 
economic and cultural culture of the real society. It is the objectification of human nature. In short, advertising culture is as complex as other cultural styles of cultural existence." The advertising culture is concise and represents the social customs, life appearance and values of the era in which it is located.

As one of the components of social culture, advertising culture not only has the common and common characteristics of other cultures, but also has its own unique personality characteristics. The process of advertising creation is the process of people sharing and co-constructing social culture. At the same time, it is also the process in which social values are continuously conveyed and the audience actively or passively accepts social culture. It is influenced by two aspects: one is the cultural background of the advertisers themselves, and the other is the cultural background of the audience. Therefore, the development of advertising reflects a changing culture. On the other hand, the development of advertising has also promoted and changed the development of social culture. Advertising culture is a kind of mass consumption culture. It comes into being with the market economy, with the mass media as the carrier and the public as the main target.

\section{The Characteristics of Modern Advertising Culture}

\subsection{Commercial Nature of Advertising Culture}

Commerciality is a basic feature of advertising culture. Advertising is produced in response to the emergence of commodity production and commodity exchange. The purpose of advertising is to sell goods. First of all, the fundamental task of advertising is to promote the goods, attract the attention of the broad audience, achieve the purpose of selling the goods or spreading their ideas and services, so as to achieve the purpose that the advertiser wants to achieve. Secondly, from the perspective of the production and operation of advertising, advertising itself is an economic activity. Especially in modern society, advertising from the conception, production to dissemination, there are professional advertising companies or production teams involved, advertising mainly invested in this. Even for public service advertisements or other non-commercial advertisements, in the process of producing advertisements, it is necessary to pay a certain fee to the production company and the media, and it is still necessary to participate in economic activities.

\subsection{Repeatability of Advertising Communication}

Modern science and technology have created the development of communication media and communication technologies. Advertising can be broadcast not only across regions, but also repeatedly on the same or different media at the same time or at different times. For example, in the past few years, "this year's festival did not receive gifts and received only melatonin"-the "Melaborin" advertisements that were accused of being vulgar and the Hengyuanxiang advertisements of "Hengyuanxiang, Yangyangyang" were using this repeated com- 
munication means, although The indiscriminate bombardment of the same information has caused people to resent this advertisement. Single people have also remembered it while they are bothered and annoyed. The products of "Ming Platinum" and "Hengyuanxiang" have become household names overnight. The advertising achieved its desired effect, and the sales of melatonin climbed.

\subsection{The Guiding Nature of Advertising Concealment}

Advertisers know that if they promote product products nakedly, they will not only attract a large audience, but also arouse their resentment but put on the beautiful cloak of "culture", which will give more rationality to product identity. Even increased the value of the product itself. In this process, advertising not only conveys product information to people, but also conveys the concept that the merchant wants to express. The advertisement has a dynamic guiding role. On the one hand, advertising influences and tries to convince a wide audience to recognize the products advertised in the advertisements, and then implement the purchase behavior. On the other hand, advertisements promote the information of the products while promoting certain values, ethics and consumption concepts, etc.

The effect of advertising is the ingenious use of the awareness of mass culture consumption. Today, people buy certain goods not only because they need it, but more importantly, to obtain a kind of psychological satisfaction and some kind of advertising in the advertisement. In the advertisement, "Starbucks" coffee is defined as a "small capital" atmosphere, and fashionable young people are rushing. The purchase of "Nike" sneakers is "s manifestation of full personality" performance, although the price is expensive, but still cannot stop the eager aspirations of the majority of young people. As the famous advertising master Bernbach said, "Advertising is essentially a persuasive art.” Therefore, advertising itself is concealed with strong orientation.

\section{Thoughts on the Connotation Characteristics of Modern Advertising Culture}

\subsection{Extension of the Theory of "Commodity Fetishism"}

Marx first proposed the theory of "commodity fetishism" in Capital. He believes that there is nothing mysterious about the use value of goods. The mystery of goods is derived from the form of goods and is derived from the exchange value. In this context, the so-called "worship of something as an idol", that is, "commodity fetishism" means giving power that the commodity itself does not have. Horkheimer pointed out: "Compared with production, people are more interested in privacy and consumption... This phenomenon has some utopian characteristics. In Utopia, production is not the key. The world of milk and honey is everywhere. The most important". The "Utopia" described by Horkheimer has the characteristics of commodity fetishism. In the atmosphere of the consumer society created by advertising, people's consumption of things is not only to sa- 
tisfy their use value, but also to satisfy people's demand for "image".

In the advertisement, the visual image created by the advertisement is pushed to the front of the screen, controlled by the business logic, which is both utilitarian and fashionable. Here, the advertising culture plays the role of the "evangelist" of the commodity fetishism. For example, in the modern fashion women's group, there is a kind of "handbag obsessiveness", that is, these women show their enthusiasm and love for famous handbags and bags such as LV, GUGGI and Prada. Their pursuit of these brand-name handbags is not only the quality of the package, but also the pursuit of famous brands [2]. The reason why handbags become the vanity of their vanity and wealth is because of the conspicuous design elements in the advertisements. The brand-name handbags have been evaded by the low-key LOGO to the present day, and the fear that LOGO is not big enough is not enough. When many fashionable women's handbags and bags with LV or distinctive GUGGI logos are swayed through the market, they are already loyal followers of the "product fetishism" conveyed in the advertisements, and their behavior has become the living advertisement of the merchants. .

Leveraging advanced media technology, the image supported by technical logic maximizes the requirements of advertisers. The multimedia platform makes the advertising information density higher, and the visual expression of advertising text is more direct. Advertisements more transform the goods described by images into a consumption concept and belief, stimulate people's excessively expanding desire for consumption, and advocate the cultivation of blind, almost crazy material worship.

\subsection{Lack of Humanistic Care}

Fistron believes that consumer culture, especially visual culture, has three functions for society: one is the function of cultural flattening, the other is the democratic function of culture, and the third is the unique economic function. In the advertising culture, advertising texts convey information and concepts in visual form. Due to the wide range of carriers and the availability of content, the public can easily obtain and possess information. The advertising culture has been democratized at some level. The public has the opportunity to accept the same image, with the same consumption opportunities, on the surface, the advertising culture is a "democratic culture."

However, it is too arbitrary to simply prove that advertising can help society achieve cultural equality and cultural democracy from the perspective of image consumption equality and media resource sharing. The image itself is constantly creating its characterized consumption ideology and way of life. The initiative of the conscious expression of advertising is still in the hands of the capital owner, and the audience is still in a passive acceptance state. In the advertising text, in pursuit of visual stimuli, advertisers maximize their technological superiority, pursue visual stimuli, exaggerate product effects, and even appear visual signs of violence and pornography, lacking humanistic care and social responsibility. 


\subsection{The Entanglement of the Audience's Sensory Instinctive Desire}

The purpose of advertising is to try to make the audience remember the products they advertise. In order to stand out in the same type of products and homogenization advertisements, many advertisers do not hesitate to play the moral and legal edge of the ball, and stimulate the audience's sensory instinct desire. If "erotic" is a kind of sentiment that fits the legal and moral scope, then "pornography" is a phenomenon of cultural anomie that is detrimental to the public order and good cultural interest. If the advertising works are quite style and not vulgar, then See how the creators of advertising can grasp the "degree" problem.

On June 9th, at the China JOY exhibition, a well-known game show in China, in order to attract audiences and create "Shantou", each game merchant sent a burly male model to exhibit women's "walls" and "shoes" activities. Although some people have played the banner of feminist liberation, the reason is that this is still a typical kind of stimulating the low-level psychological needs of the audience, creating a kitsch aesthetic culture atmosphere to stimulate consumption. This kind of sexually suggestive, sexually conscious cultural output further confuses the audience's perception of social ethics, especially the establishment of adolescent values will have a negligible impact.

In addition, the advertisement also uses the audience's memory of extreme emotions, the use of adolescents' rebellious psychology, and so on, which embodies the entanglement of the sensory instinctive desire of the audience [3]. This kind of advertising culture embodies the lack of moral evaluation standards and the confusion of the audience in the multicultural background. In the era of information explosion, the audience lacked prudent thinking, and the multicultural shock created the chaos of social audience value evaluation standards, which made the cultural anomie advertisements extremely "inclusive".

\section{Declaration}

This paper is only an interim achievement in the research of Li Bai cultural communication under the Belt and Road (Project No. LB19-B20).

\section{Conflicts of Interest}

The author declares no conflicts of interest regarding the publication of this paper.

\section{References}

[1] Wang, C.M. (2006) Research on Cultural Connotation of Advertising. Hohai University, Nanjing.

[2] Chi, Q. (2010) Reflection on Advertising Visual Culture in the Context of Consumer Society. Southeast Communication, 7, 131-133.

[3] Zhang, D.Y. (2004) Critical Research: An Alternative Interpretation of Advertising Culture Communication. Modern Communication, 5, 84-87. 